\title{
Water and nitrogen input optimization for jujube trees under surge root irrigation based on weighted grey correlation model
}

\author{
Zhiguang Dai ${ }^{1,2}$, Liangjun Fei ${ }^{1 *}$, Yun Zhong ${ }^{1}$, Deliang Huang ${ }^{1}$ \\ (1. Institute of Water Resources Research, Xi'an University of Technology, Xi'an 710048, China; \\ 2. School of Hydraulic and Ecological Engineering, Nanchang Institute of Technology, Nanchang 30099, China)
}

\begin{abstract}
In order to obtain the optimal input of water and nitrogen (W\&N) suitable for the jujube trees in Northern Shaanxi, 12 treatments had been set in the demonstration base of micro-irrigation jujube tree of Mizhi County in 2014-2015 through field experiment of jujube trees under surge root irrigation (SRI), in which three soil moisture levels (high moisture level W1: 60\%-85\% $\theta$, middle moisture level W2: 50\%-75\% 0 , low moisture level W3: 40\%-65\% $\theta$ ) and four nitrogen input levels (high nitrogen F75: $0.75 \mathrm{~kg} /$ plant, middle nitrogen F50: $0.50 \mathrm{~kg} /$ plant, low nitrogen F25: $0.25 \mathrm{~kg} /$ plant, no nitrogen F0: $0.00 \mathrm{~kg} / \mathrm{plant}$ ) were set. Through analyzing the effects of different W\&N inputs on the yield, net income (NI) and W\&N utilization efficiency (WUE and NUE) of jujube trees and establishing a weighted grey correlation model, the optimization of W\&N input for jujube trees could be achieved under SRI. Results showed that different W\&N inputs had significant influences on yield, NI, WUE and NUE. Along with the increase of soil moisture content, the yield and NUE increased, while WUE decreased gradually, and the NI had the tendency to increase first and then decrease. Along with the increase of nitrogen input, the yield, NI and WUE had the tendency to increase first and then decrease while the NUE decreased significantly, and the yield, NI, WUE and NUE could not reach the maximum at the same time. Through the study on the grey correlation model of jujube tree's comprehensive benefit based on the yield, NI, WUE and NUE, results showed the comprehensive benefit of jujube trees was significantly different when W\&N input was different, and the gray correlation degree of W2F25 treatment was the highest in two years, which means that the soil moisture content of $50 \%-75 \% \theta$ and nitrogen input of $0.25 \mathrm{~kg} / \mathrm{plant}$ was the optimal W\&N input for jujube trees under SRI in Northern Shaanxi area.
\end{abstract}

Keywords: surge root irrigation, input of water and nitrogen, jujube tree, comprehensive benefit, grey correlation model DOI: $10.25165 /$ j.ijabe.20191203.3541

Citation: Dai Z G, Fei L J, Zhong Y, Huang D L. Water and nitrogen input optimization for jujube trees under surge root irrigation based on weighted grey correlation model. Int J Agric \& Biol Eng, 2019; 12(3): 45-51.

\section{Introduction}

Jujube is one of the major economic trees in Northern Shaanxi, which has been widely planted for its high economic benefit, easy management and strong drought tolerance ${ }^{[1]}$. At present, the main problem in Northern Shaanxi lies in drought and soil erosion where most local farmers still adopt the traditional flood irrigation or furrow irrigation method which has disadvantages of low fresh water using efficiency, serious waste of water resources and huge losses of available nutrients ${ }^{[2,3]}$. With the increasing shortage of water resources, it is urgent to develop water-saving irrigation.

SRI is a new micro-irrigation technology. Research showed that SRI can improve the yield, quality and water using efficiency of crops significantly, and is especially suitable for the irrigation of economic trees ${ }^{[4-6]}$. Fertilization under SRI is a new agricultural technology that combines fertilizing with SRI and delivers water and fertilizer to the root zone of crops by SRI emitter to reduce the

\section{Received date: 2018-06-05 Accepted date: 2019-04-13}

Biographies: Zhiguang Dai, $\mathrm{PhD}$, research interest: theory and new technology of water- saving irrigation, Email: daizhiguang100@163.com; Yun Zhong, PhD candidate, research interest: theory and new technology of water - saving irrigation, Email: 784471206@qq.com; Deliang Huang, Master, research interest: theory and new technology of water-saving irrigation, Email: 1176655696@qq.com.

*Corresponding author: Liangjun Fei, Professor, research interest: theory and new technology of water-saving irrigation. Xi'an University of Technology, No.5, Jinhua South Road, Xi'an 710048, Shaanxi, China. Tel: +8613186181693, Email: feiliangjun2008@163.com. loss of water and fertilizer, and improve the crop yield and water-fertilizer using efficiencies significantly. Currently, scholars have conducted a large number of studies on the effect to the crops by irrigation and fertilization such as the effect to the jujube yield and quality by drip irrigation and fertilization. Liu et al. ${ }^{[7]}$ reported that when the amount of irrigation and fertilization reached at $900 \mathrm{~mm}$ and $1500-1800 \mathrm{~kg} / \mathrm{hm}^{2}$, respectively, the jujube yield and quality achieved optimal. However, Wang et al. ${ }^{[8]}$ showed that the optimal irrigation and fertilization amount for drip irrigation and fertilization of jujube trees should be $815 \mathrm{~mm}$ and $400 \mathrm{~kg} / \mathrm{hm}^{2}$ respectively. Such result revealed that there is a big difference on the optimal amount of irrigation and fertilization of jujube trees. Relevant scholars has drawn the conclusions through coupling experiment of water and fertilizer on cottons that the rational W\&N input are key to improve cotton's yield and NI, and there is a big difference to the influences on the cotton yield and using efficiency of water and fertilizer among different W\&N input $^{[9-11]}$. Pan et al. ${ }^{[12]}$ found that under the drip irrigation and fertilization condition, suitable water and fertilizer conditions could improve the root activity of banana, so that the fertilizer use efficiency could be improved. Pan et al. ${ }^{[13]}$ found that comparing to water, nitrogenous fertilizer contributed more to the rice yield and NUE based on the research of influences to the rice yield, WUE and NUE under different W\&N input, where the mutual effect between water and fertilizer was less obvious. Niang et al. ${ }^{[14]}$ showed that the influence of mutual effect between water and fertilizer on the rice could reach the significant level. Hossain et al. ${ }^{[15]}$ studied the influence to the yield and quality of cucumber 
under the coupling of water-nitrogen-potassium and the result showed that yield of cucumber changed upon different inputs of water, nitrogen and potassium. The influence of water to the accumulated dry matter inside cucumber had also reached a significant level, whereas the influence on leaves was of less significant. Rathore et al. ${ }^{[16]}$ studied the influence of different W\&N input on the yield, WUE and NUE of wheat, which showed that a suitable water deficit could improve the WUE greatly under the condition of ensuring that wheat yield did not decreased significantly.

All of the above studies showed that the water and fertilizer input have great influence on crops, so the optimization of the input is of great importance. In recent years, along with the widely application of the mathematical methods and models in fields of water-saving irrigation technology and water resources evaluation-such as grey correlative grade, fuzzy evaluation and clustering analysis, etc. ${ }^{[17-20]}$, the grey correlation model becomes a unique mathematical analysis method initiated by a famous scholar professor Deng ${ }^{[21]}$. In recent years, more and more reports on multi-program optimization based on grey correlation evaluation model have been published, and it has also been widely applied in agricultural field. For example, Yang et al. ${ }^{[22]}$ used this model to optimize the crop straw comprehensive utilization plan in Heilongjiang Province and achieved expected results; Wang et al. ${ }^{[23]}$ optimized the furrow irrigation method of summer maize by this model and got satisfactory result; Zhao et al. ${ }^{[24]}$ analyzed the performance index of wheat no-tillage planter by this model, and received the optimal operation method of wheat no-tillage planter. All of the above studies showed that the grey correlation model could be used for the evaluation and optimization of multi-program, but the study on the optimization of W\&N input for crops based on grey correlation model was rarely reported. In addition, the influences of weight of evaluation index on evaluation result have been considered by many scholars through application. However, the weight is mainly determined by the method of analytic hierarchy process or expert prediction method which may be influenced by subjective factors and depends to a large extent on personal experience, so that the possibility of serious one-sidedness aroused by individual decision makers cannot be avoided ${ }^{[25,26]}$.

This study aims to comprehensively improve jujube yield and its economic benefit, water and fertilizer using efficiency under the technology of SRI, and study the influences of different soil moisture content and different nitrogen input coupling on the jujube yield, NI, WUE and NUE in Northern Shaanxi. Moreover, adopting the objective weighting method based on the result to determine the weights of each evaluation index, establishes the weighted grey correlation model based on jujube yield, NI, WUE and NUE, thus to comprehensively evaluate different W\&N input programs and obtain the optimal $\mathrm{W} \& \mathrm{~N}$ input. This study was expected to provide the new thoughts for the effective water and fertilizer integrated management of surge root irrigation for jujube trees in Northern Shaanxi area.

\section{Materials and methods}

\subsection{Experimental area}

The experiment was conducted at micro-irrigation jujube demonstration base in Mizhi County, Yulin City, Shaanxi Province during the jujube's phonological periods in 2014 and 2015. The area has temperate semi-arid climate characteristics with a perennial mean temperature of $8.8^{\circ} \mathrm{C}$ and a frost-free season of $162 \mathrm{~d}$. The soil texture is alkaline sandy loam soil with a $\mathrm{pH}$ of
8.6. The average volume weight of $0-60 \mathrm{~cm}$ soil layer is $1.21 \mathrm{~g} / \mathrm{cm}^{3}$ with a field water holdup rate of $22 \%$ and the organic content of $2.10 \mathrm{~g} / \mathrm{kg}$, the effective $\mathrm{N}, \mathrm{P}$ and $\mathrm{K}$ contents of $34.74 \mathrm{mg} / \mathrm{kg}$, $2.91 \mathrm{mg} / \mathrm{kg}$ and $101.90 \mathrm{mg} / \mathrm{kg}$ respectively- A poor soil in general.

\subsection{Experiment design}

The experiment area locates in the jujube plantation with test varieties of "Lizao jujube" that were planted in 2008. The planting density is $1665 \mathrm{plants} / \mathrm{hm}^{2}$ and the height of tree various in 2.0-2.5 m. Test trees grow well and uniforms in size with mere individual differences. The water supply mode adopts SRI, where 2 irrigation emitters were embedded in left and right for each jujube with a horizontal distance of $25 \mathrm{~cm}$ to the trunk, embed depth of $35 \mathrm{~cm}$ and flow rate of $5 \mathrm{~L} / \mathrm{h}$ (Figure 1). The soil coring method is adapted to the investigation on root distribution which shows that more than $85 \%$ of water absorbing roots $(d<2 \mathrm{~mm})$ distributes within a depth of $60 \mathrm{~cm}$, so the planned wetting layer for this experiment is chosen at the depth of $60 \mathrm{~cm}$.
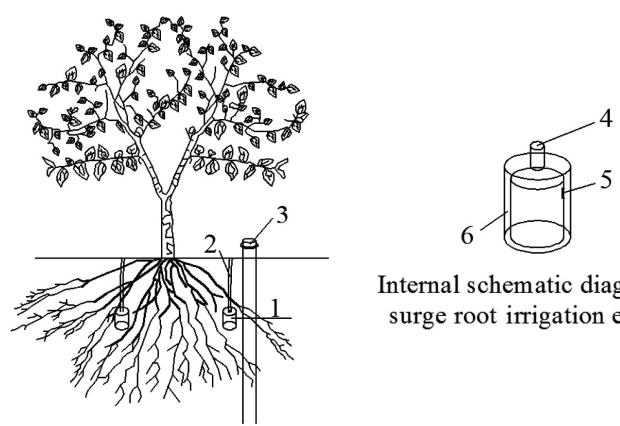

Internal schematic diagram of surge root irrigation emitter

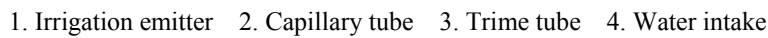

5. Outlet 6. Labyrinth runner

Figure 1 Schematic diagram of surge root irrigation for jujube trees

Two factors were set for the experiment - soil moisture content and nitrogen input. To prevent the excessive growth of trees and promote the fruiting, no irrigation was conducted during the blossoming and fruiting period. Due to the local big rainfall and quickly dropping temperature in period of fruit maturity, the physiological activity of jujube turns slow, so that no irrigation was conducted in this period too. In this experiment, only two phenological stages, germination and leaf-spreading stage and fruit bulking stage, were selected for water control with three soil moisture content levels - W1 $(60 \%-85 \% \theta)$, W2 $(50 \%-75 \% \theta)$ and W3 $(40 \%-65 \% \theta)$, simulating respectively mild, moderate and severe water deficit situations of soil moisture. According to investigation, the frequently-used nitrogen input on jujube trees by local farmers is $0.5 \mathrm{~kg} / \mathrm{plant}$. Based on this, four different nitrogen input gradients $(0.75 \mathrm{~kg} /$ plant, $0.5 \mathrm{~kg} /$ plant, $0.25 \mathrm{~kg} /$ plant and $0.00 \mathrm{~kg} /$ plant) were set in the experiment with 12 treatments in total. Three jujube trees were selected as a treatment. The experiment scheme is shown in Table 1. The fertilization of trees in this experiment area was carried out twice a year- in initial germination period (base fertilizer) and in early fruit bulking period (additional fertilizer). Except for the differences of nitrogen input, the annual input and fertilizing methods of all the organic fertilizer treated, phosphate and potassium fertilizers were the same. Organic fertilizer of $1665 \mathrm{~kg} / \mathrm{hm}^{2}$ was added annularly by hole application $20 \mathrm{~cm}$ away from the main trunk of trees in the early April, then monopotassium phosphate of $1000 \mathrm{~kg} / \mathrm{hm}^{2}$, potassium sulphate of $1000 \mathrm{~kg} / \mathrm{hm}^{2}$ and $50 \%$ urea in each treatment were applied in forms of fertilizer fluid through Venturi applicator. The rest $50 \%$ urea were applied in the form of additional fertilizer 
during the early fruit bulking period. The treatment methods such as manual pesticide spray, pruning, weeding, fruit thinning and bagging were all the same.

Table 1 Soil water content for each growth stage and nitrogen input for all treatments

\begin{tabular}{|c|c|c|c|c|c|}
\hline \multirow[b]{2}{*}{ Treatment } & \multicolumn{4}{|c|}{ Soil water content $/ \% \theta$} & \multirow{2}{*}{$\begin{array}{l}\text { Nitrogen } \\
\text { input } \\
/ \mathrm{kg} \cdot \text { plant }^{-1}\end{array}$} \\
\hline & $\begin{array}{c}\text { Germination/ } \\
\text { frondescence } \\
\text { stage }\end{array}$ & $\begin{array}{c}\text { Flowering/ } \\
\text { fruit-bearing } \\
\text { stage }\end{array}$ & $\begin{array}{l}\text { Fruit- } \\
\text { filling } \\
\text { stage }\end{array}$ & $\begin{array}{c}\text { Fruit } \\
\text { maturation } \\
\text { stage }\end{array}$ & \\
\hline W1F75 & $60-85$ & - & $60-85$ & - & 0.75 \\
\hline W1F50 & $60-85$ & - & $60-85$ & - & 0.50 \\
\hline W1F25 & $60-85$ & - & $60-85$ & - & 0.25 \\
\hline W1F0 & $60-85$ & - & $60-85$ & - & 0.00 \\
\hline W2F75 & $50-75$ & - & $50-75$ & - & 0.75 \\
\hline W2F50 & $50-75$ & - & $50-75$ & - & 0.50 \\
\hline $\mathrm{W} 2 \mathrm{~F} 25$ & $50-75$ & - & $50-75$ & - & 0.25 \\
\hline $\mathrm{W} 2 \mathrm{~F} 0$ & $50-75$ & - & $50-75$ & - & 0.00 \\
\hline W3F75 & $40-65$ & - & $40-65$ & - & 0.75 \\
\hline W3F50 & $40-65$ & - & $40-65$ & - & 0.50 \\
\hline W3F25 & $40-65$ & - & $40-65$ & - & 0.25 \\
\hline W3F0 & $40-65$ & - & $40-65$ & - & 0.00 \\
\hline
\end{tabular}

\subsection{Observation and index of experiment}

\subsubsection{Meteorological data}

Real-time monitor was done by the automatic meteorological station in the experiment area. Data includes temperature, relative air humidity, atmospheric pressure, solar radiation intensity, wind speed, wind direction, rainfalls, etc.

2.3.2 Index of yield

Jujube fruit was weighed immediately after harvest and the yield was calculated based on actual harvest, then converted into hectare yield. The harvest was dated on 11-12 October, 2014 and 15-16 October, 2015

\subsubsection{Index of NI}

After jujube's harvest in current year, total income was calculated according to the local purchasing price, deducting water, electricity, manpower and the converted annual investment of the project, etc.- remains the NI of jujube trees.

\subsubsection{Index of water using}

The water consumption index consists of water consumption (ET) and water use efficiency (WUE). Moisture content within soil layer of $0-60 \mathrm{~cm}$ was measured every $7 \mathrm{~d}$ by tubular Trime-T3 system, and then was converted into mass moisture content. The instrument was corrected regularly by soil-sampling and drying method to ensure the accuracy of measurement.

(1) Calculation formula of water consumption ${ }^{[27]}$ :

$$
E T=P_{r}+U+I-D-R-\Delta W
$$

where, $E T$ is water consumption, $\mathrm{mm} ; P_{r}$ is effective rainfall, $\mathrm{mm}$; $U$ is groundwater recharge, $\mathrm{mm} ; I$ is irrigation amount, $\mathrm{mm} ; D$ is deep seepage, $\mathrm{mm} ; R$ is runoff amount, $\mathrm{mm} ; \Delta W$ is variation of soil water storage from the beginning to the end of this experiment, $\mathrm{mm}$.

The jujube yard for the experiment locates in mountains of Loess Plateau of Northern Shaanxi, where is over $50 \mathrm{~m}$ to the groundwater level, and there's no runoff occurred on the surface during tree's growing period. So both $U$ and $R$ can be ignored, then Equation (1) can be simplified as following:

$$
E T=P_{r}+I-D-\Delta W
$$

The average soil moisture content was measured before the experiment and after the harvest, and $\Delta W$ was the difference of soil moisture content between post-harvest and pre-harvest in wetting layer. The deep seepage in this experiment was caused mainly by the rain which can be obtained by further measure the soil water content before and after rain.

(2) Calculation formula of water use efficiency $(W U E)^{[28]}$.

$$
W U E=Y / E T
$$

where, $Y$ is yield, $\mathrm{kg} / \mathrm{hm}^{2}$.

2.3.5 Index of nitrogen fertilizer using

Calculation formula of nitrogen fertilizer use efficiency $(N U E)^{[28]}$ :

$$
N U E=Y / F
$$

where, $N U E$ is nitrogen use efficiency, $\mathrm{kg} / \mathrm{kg} ; Y$ is jujube yield, $\mathrm{kg} /$ plant; $F$ is nitrogen input, $\mathrm{kg} /$ plant.

\subsection{Comprehensive assessment on grey correlation}

Based on the gray theory, weighted grey correlation model of different W\&N input can be established.

(1) Determine the reference sequence and comparative sequence

Reference sequence: Extract the combination of the optimal parameters for each evaluation index from 8 treatments, i.e. $Y=\left(y_{11}\right.$, $\left.y_{12}, \ldots, \mathrm{y}_{1 n}\right), n$ means the quantity of evaluation indexes.

Comparative sequence: Combinations of each evaluation index corresponding to the 8 treatments above, $X i=\left(x_{i 1}, x_{\mathrm{i} 2}, \ldots, x_{i j}\right), x_{i j}$ means the $j^{\text {th }}$ evaluation index parameter of $i^{\text {th }}$ comparative sequence.

(2) Initialization processing of index value

Original data were processed dimensionless by extremum method, which means the dimensionless variety can be the ratio of the statistical value $x_{i j}$ to the maximum value $\mathrm{x}$ for each evaluation index, $y_{i j}^{\prime}=x_{i j} / x$.

(3) Confirm on grey correlation matrix

Taking $y_{\mathrm{ij}}^{\prime}$ as the subsequence to calculate the correlation grade $r_{i j}$, the evaluation matrix of grey correlative grade can be obtained.

$$
r_{i j}=\frac{\min _{n} \min _{m}\left|y_{o j}^{\prime}-y_{i j}^{\prime}\right|+\lambda \max _{n} \underset{n}{\max }\left|y_{o j}^{\prime}-y^{\prime}\right|}{\left|y_{o j}^{\prime}-y^{\prime}\right|+\lambda \max _{n} \max _{m}\left|y_{o j}^{\prime}-y^{\prime}\right|}
$$

where, $r_{i j}$ is the correlation coefficient of $\mathrm{j}^{\text {th }}$ evaluation index of $\mathrm{i}^{\text {th }}$

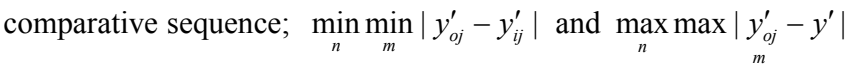
refer to the second order minimum difference and second order maximum difference respectively; $\lambda$ is the distinguishing coefficient (the smaller the value were, the better the resolution could be), usually $0.5^{[23]}$.

(4) Index weight

This study adopts the variation coefficient method of objective weight to determine the weights of each evaluation index. Due to the difference of dimensions of each index, direct comparisons were difficult to achieve. So the variable coefficient of each index was used to measure the difference degree of each index:

$$
V_{j}=\frac{a_{j}}{\bar{x}_{j}}
$$

where, $V_{j}$ is the variable coefficient of $\mathrm{j}^{\text {th }}$ index; $a_{j}$ is the standard deviation of $\mathrm{j}^{\text {th }}$ index; $\bar{x}_{j}$ is the average value of $\mathrm{j}^{\text {th }}$ index.

Weight $w_{j}$ for each index:

$$
w_{j}=\frac{V_{j}}{\sum_{j=1}^{n} V_{j}}
$$

(5) Calculate the grey correlative grade value of each program 


$$
D_{i}=\sum_{j=1}^{n} \mathrm{w}_{j} r_{i j}
$$

SPSS (v.21.0, 2013) software was adopted for variance analysis, further Duncan multiple comparison should be conducted on the occurance of remarkable difference $(p<0.05)$.

\section{Results}

\subsection{Effects of different $W \& N$ inputs on yield}

As shown in Figure 2, with the increase of soil moisture content under same nitrogen inputs, jujube yields increased gradually in two years, and the increase amplitude varied within different phases. When the soil moisture increased from W3 to $\mathrm{W} 2$, the yield increased significantly. When the soil moisture continuously increased from W2 to W1, the yield kept increasing but the difference is not significant, which explained the soil moisture content of $40 \%-65 \% \theta$ will inhibit the jujube yield significantly and be not conducive to jujube production. Under the same soil moisture contents, with the increase of nitrogen input, the jujube yield has a tendency to increase first and then decrease in two years. Comparing with medium nitrogen, the jujube yields were decreased greatly under treatments of both nitrogen-increasing and non-nitrogen, which explains that only suitable nitrogen can improve the jujube yield effectively. In two years, the jujube yield under W1F50 treatment has achieved the maximum of $16916.40 \mathrm{~kg} / \mathrm{hm}^{2}$ and $16333.65 \mathrm{~kg} / \mathrm{hm}^{2}$ respectively. Comparing with W1F75 treatment with maximum W\&N input, though the yield increasing did not exceed $1.00 \%$, the nitrogen fertilizer saved $416.25 \mathrm{~kg} / \mathrm{hm}^{2}$, which means that W1F50 can guarantee the yield increasing or prevent from massive decreasing under conditions of lowering the nitrogen fertilizer input.
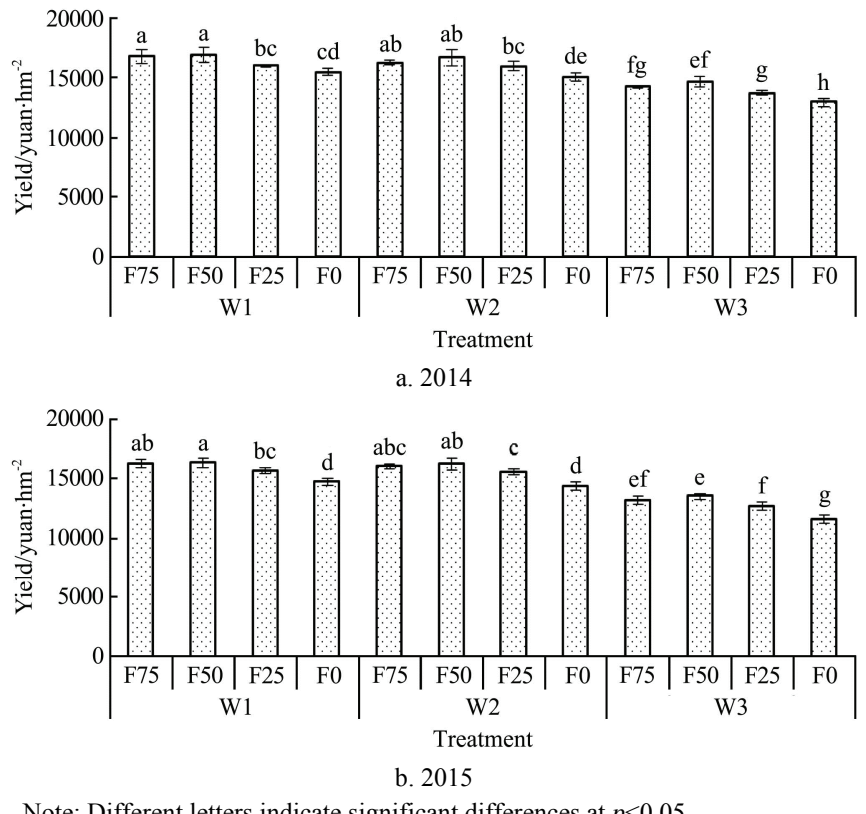

Note: Different letters indicate significant differences at $p<0.05$.

Figure 2 Jujube yield for the various soil-water contents and rates of nitrogen application in 2014 and 2015

\subsection{Effects of different $W \& N$ inputs on NI}

Figure 3 shows jujube's NI corresponding to different W\&N inputs. Different W\&N inputs affects greatly on jujube's NI. Under same W\&N input, with the increase of soil moisture, the general variation tendency of NI increased first and then decreased. When the soil moisture content level lowered, the jujube yield was restricted, so the income of local farmers lowered accordingly. Whereas, under bigger soil moisture content, though the jujube yield increases to some extent, the NI lowered because of the exceeding expenses to the earnings in this period. Under same soil moisture content, the trend of nitrogen input was consistent with the yield of jujube - increase first and then decrease. In two years, the jujube's NI turned out to be between 24359.0-31618.4 and 19247.4-28663.0 Yuan $/ \mathrm{hm}^{2}$, the increase amplitude comparing to highest and lowest NI respectively were $29.80 \%$ and $48.92 \%$, which explains that irrational W\&N inputs can lower farmer's income significantly. Comparing with W3, the water expenses of W1 treatment in two years increased by 2414.25 and 2713.95 Yuan $/ \mathrm{hm}^{2}$ respectively, and the increase amplitudes of NI were over 4200 Yuan, the loss caused by nitrogen input difference didn't exceed 3500 Yuan. So the increase of irrigation amount has more significant effect to the increasing income of local farmers comparing with nitrogen input, which can be another important reason why the local farmers were reluctant in saving water.
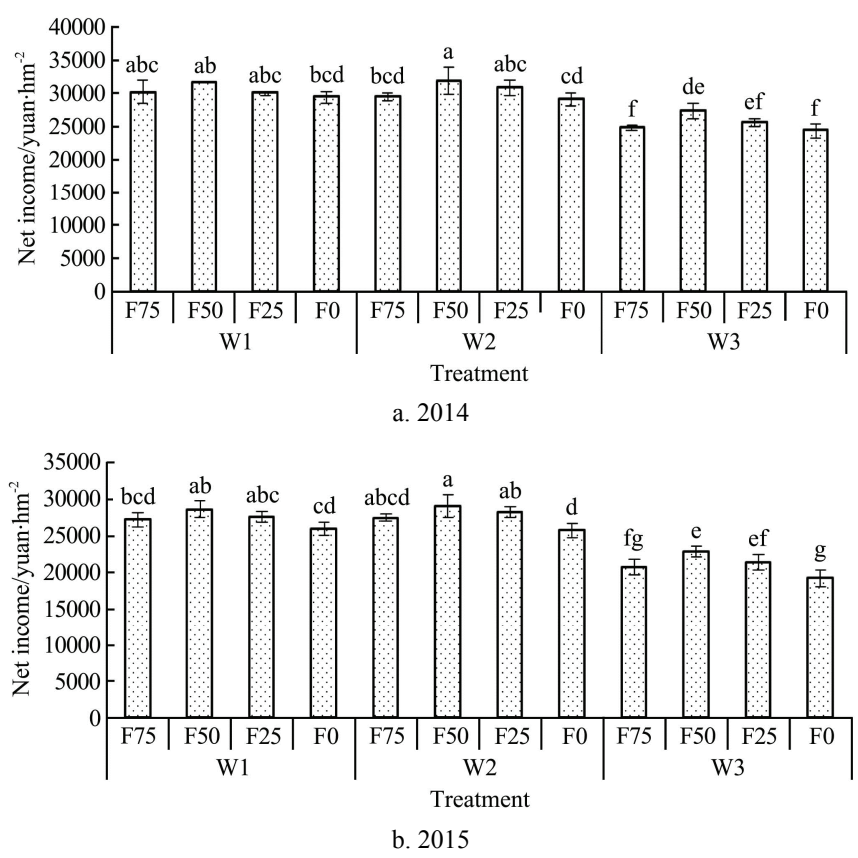

Figure 3 Net income of jujube for the various soil water contents and nitrogen inputs in 2014 and 2015

\subsection{Effects of different W\&N Inputs on WUE}

Figure 4 shows jujube WUE corresponding to different W\&N inputs. Under same soil moisture contents, with the increase of nitrogen input, jujube WUE had a tendency to increase first and then decrease. Comparing with F50, the jujube WUE under F0 treatment decreased greatly, whereas the decrease amplitude of WUE under F75 treatment wasn't that obvious. Under same nitrogen input, with the increase of soil moisture content, the tendency of WUE in two years turned out to decrease gradually. The WUE under W1 treatment had greater decrease than W3 treatment (except F75 and F0 levels in 2014), but with little difference to that under W2 treatment. In two years, the jujube WUE under W3F50 treatment reached the maximum of $3.75 \mathrm{~kg} / \mathrm{m}^{3}$ and $4.43 \mathrm{~kg} / \mathrm{m}^{3}$ respectively, and those under $\mathrm{W} 1 \mathrm{~F} 0$ treatment were of the lowest value of $3.23 \mathrm{~kg} / \mathrm{m}^{3}$ and $3.57 \mathrm{~kg} / \mathrm{m}^{3}$ respectively, $16.31 \%$ and $24.26 \%$ lower than the maximum values.

\subsection{Effects of different W\&N inputs on NUE}

Figure 5 shows changes of jujube NUE corresponding to different $\mathrm{W} \& \mathrm{~N}$ inputs. According to the figure, under same nitrogen input with the increase of soil moisture content, the tendency of jujube NUE turned to increase gradually. Jujube NUE under W3 treatment decreased much more than those under 
W2 treatment, yet with little difference to W1 treatment. Under same soil moistures, with the increase of nitrogen input, the jujube NUE decreased greatly, and the difference among F75, F50 and F25 treatment reached a significant level. The maximum values of jujube NUE in two years were $38.48 \mathrm{~kg} / \mathrm{kg}$ and $37.56 \mathrm{~kg} / \mathrm{kg}$ respectively, under corresponding treatments of W1F25. The minimum values of jujube NUE were $13.45 \mathrm{~kg} / \mathrm{kg}$ and $13.00 \mathrm{~kg} / \mathrm{kg}$ respectively, under corresponding treatments of W1F75 with decrease amplitudes of $186.10 \%$ and $188.92 \%$ respectively to the maximum value.
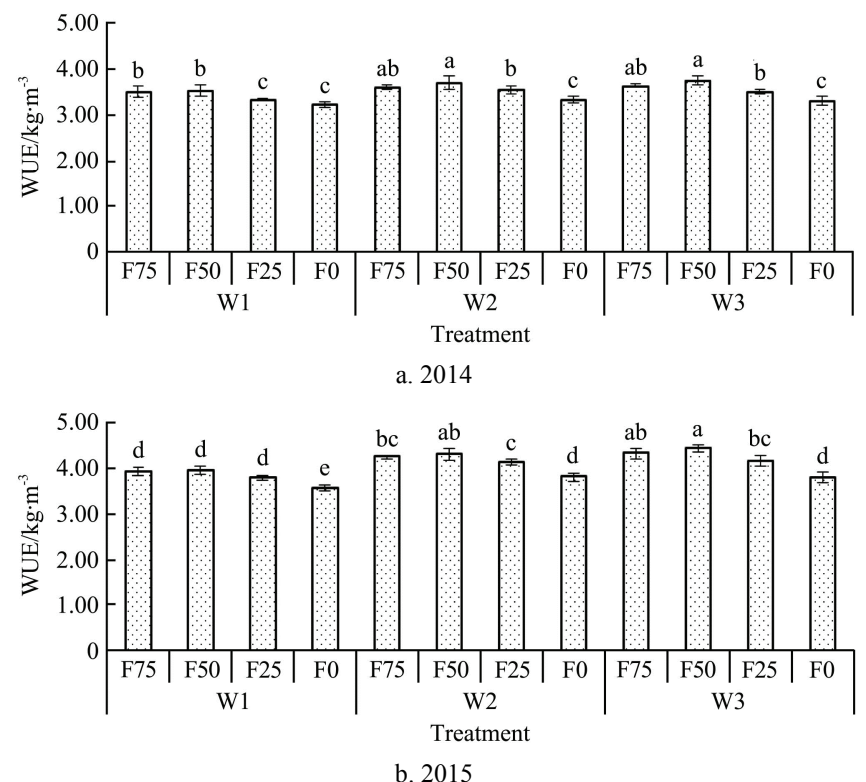

Figure 4 Jujube $W U E$ for the various soil water contents and nitrogen inputs in 2014 and 2015
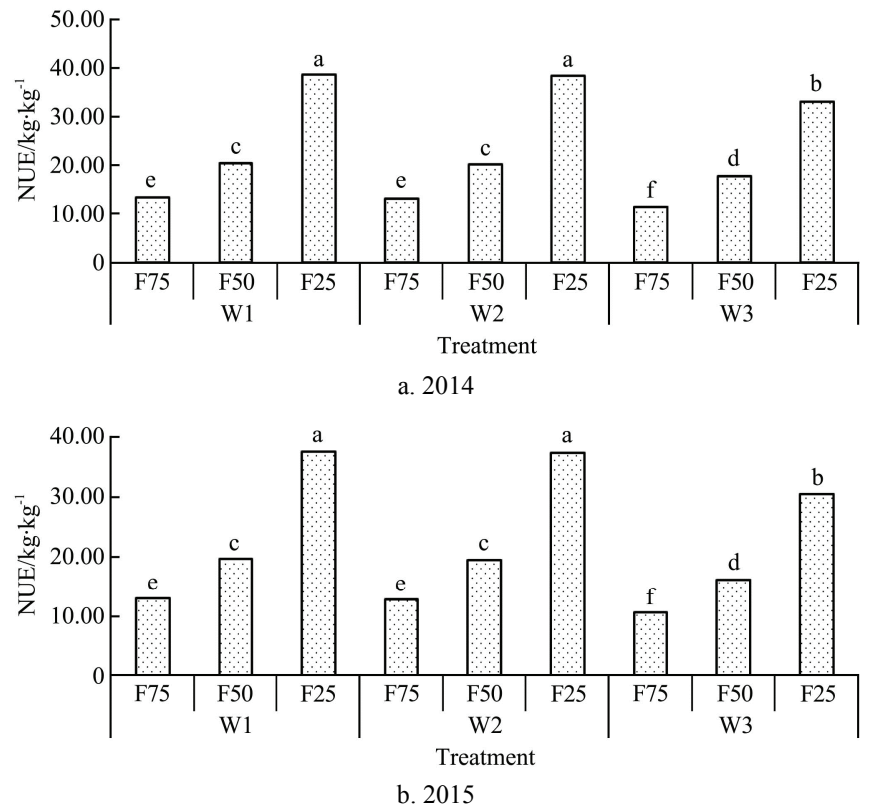

Figure 5 Jujube NUE for the various soil water contents and nitrogen inputs in 2014 and 2015

\subsection{Evaluation of grey correlation based on comprehensive} benefits

In comparison, the treatments corresponding to the maximum value of jujube yield, NI, WUE and NUE were different. Trade-offs should be carried out among those treatments in actual plantation. This study uses grey correlation evaluation method to study W\&N management method for the maximization of jujube yield, NI, WUE and NUE comprehensive benefits.

\subsubsection{Weight of each index}

Original data of each index of jujube comprehensive benefits was adopted to calculate by Equations (6) and (7). The confirmed weights of each evaluation index can be seen in Table 2. The jujube NUE weighed foremost in 2 years, and then came the jujube's NI. The weight of WUE was the last one. The result showed that the order of influences on comprehensive evaluation result is NUE, NI, yield and WUE.

Table 2 Coefficient of variation (CV) and weight for evaluation index of comprehensive benefit

\begin{tabular}{|c|c|c|c|c|c|c|c|c|}
\hline \multirow{2}{*}{ Year } & \multicolumn{2}{|c|}{ Yield } & \multicolumn{2}{|c|}{ Net income } & \multicolumn{2}{|c|}{ WUE } & \multicolumn{2}{|c|}{ NUE } \\
\hline & $\mathrm{CV}$ & Weight & $\mathrm{CV}$ & Weight & $\mathrm{CV}$ & Weight & $\mathrm{CV}$ & Weight \\
\hline 2014 & 0.08 & 0.11 & 0.09 & 0.13 & 0.03 & 0.05 & 0.48 & 0.71 \\
\hline 2015 & 0.10 & 0.13 & 0.13 & 0.17 & 0.05 & 0.07 & 0.48 & 0.64 \\
\hline
\end{tabular}

3.5.2 Evaluation of grey correlation

Taking yield, NI, WUE and NUE as the comprehensive evaluation index of jujube trees, the referential sequences respectively were $\mathrm{Y}_{2014}=(16916.4,31884.75,3.75,38.48)$ and $\mathrm{Y}_{2015}=(16333.62,29179.13,4.43,37.56)$. Under dimensionless method to each index and according to Equation (5), $\min _{n} \min _{m}\left|y_{o j}^{\prime}-y_{i j}^{\prime}\right|$ in two years were both zero, and $\max _{n} \max \left|\underset{m}{y_{o j}^{\prime}}-y^{\prime}\right|$ were 0.704 and 0.719 respectively, then the grey correlation matrix of each evaluation index on comprehensive benefits in 2014 and 2015 can be obtained. The grey correlative grades of jujube comprehensive benefits under each treatment could be determined by substituting the index weights in Table 2 into Equation (8) (shows in Figure 3). From Figure 3, little difference could be found between comprehensive evaluation precedence of each treatment in 2014 and 2015. The precedence of W2F25 treatment was the highest, and the precedence corresponding to W3F75 treatment was the lowest, which explains that W\&N management method with $50 \%-75 \% \theta$ soil moisture content and $0.25 \mathrm{~kg} /$ plant nitrogen input can optimize the jujube comprehensive benefits, while jujube comprehensive benefit can be the worst with $40 \%-65 \% \theta$ soil moisture content and $0.75 \mathrm{~kg} / \mathrm{plant}$ nitrogen input.

Table 3 Grey correlation degree for different treatments

\begin{tabular}{ccccc}
\hline \multirow{2}{*}{ Treatment } & \multicolumn{3}{c}{2015} \\
\cline { 2 - 5 } & Correlation degree & Position & Correlation degree & Position \\
\hline W1F75 & 0.514 & 6 & 0.546 & 7 \\
W1F50 & 0.585 & 5 & 0.614 & 5 \\
W1F25 & 0.954 & 2 & 0.945 & 2 \\
W2F75 & 0.499 & 8 & 0.551 & 6 \\
W2F50 & 0.587 & 4 & 0.627 & 4 \\
W2F25 & 0.960 & 1 & 0.952 & 1 \\
W3F75 & 0.440 & 9 & 0.452 & 9 \\
W3F50 & 0.504 & 7 & 0.506 & 8 \\
W3F25 & 0.703 & 3 & 0.650 & 3 \\
\hline
\end{tabular}

\section{Discussion}

This study showed that within a certain range of $\mathrm{W} \& \mathrm{~N}$, the crops yield and NI grow with the increase of W\&N input, yet the yield and NI had a tendency to decrease when exceeding a certain threshold, so that only suitable W\&N conditions could guarantee the highest yield and NI. The same conclusion has been drawn by 
other scholars ${ }^{[29-32]}$. Since the irrigation and fertilization has changed the soil's water and nutrient environment, there has been a positive correlation between root growth and soil moisture status within a certain range. Both water deficiency and water excessiveness can change the size, quantity and distribution of crops root, the absorption of water and nutrient by root and the migration of nutrient towards to the root surface can be affected, too. Then the canopy growth and development, and nutrient utilization can be affected to lower the crops yield ${ }^{[33,34]}$. A suitable soil moisture condition can be beneficial to improve stomatal conductance of crops. Under this circumstance, additional application of nitrogen fertilizer will be beneficial to increase leaf's chlorophyll content and accelerate photosynthesis to improve crops yield.

It is also observed that jujube WUE had negative correlation relationship with irrigation amount and positive correlation relationship with fertilizing amount. The influences on NUE by water and fertilizer application was opposite to those of WUE, which is because the water production function of crops was a parabola going downwards. In the bigger irrigation amount, the smaller increase amplitude of unit water amount leads to smaller WUE. Whereas, with same water condition, increasing the nitrogen fertilizer moderately could help the crop yield to increase, then the WUE grows. The variation tendency of NUE was the same - when nitrogen input was smaller, the yield increasing effect of nitrogen fertilizer was significant and the NUE was greater. With the gradually increase of nitrogen input, the yield increasing effect of nitrogen fertilizer decreased gradually, so the NUE had a decrease tendency. With same nitrogen input, increasing water moderately could help the crop yield grow, so the NUE had positive correlation relationship with irrigation amount. The same conclusion has also been drawn by Xing et al. ${ }^{[35]}$ in related studies.

This study adopted the weighted grey correlation model to evaluate the advantages and disadvantages of different W\&N input programs with comparisons of traditional average grey correlation grades, taking consideration of the influence of evaluation index weight on correlation degrees. The isotonicity of the model ensures the objectiveness of the evaluation results. Several coefficient methods are adopted in determination of the weight in the model which can eliminate the influences of measurement scale and dimension, and can avoid subjective tendencies of expert weighting method ${ }^{[36,37]}$. This is an objective weighting method. The research obtains the grey correlative grade of each treatment through the weighted grey correlation method, and the result shows that the W2F25 treatment has highest grey correlative grade. By comparison, it shows that although the treatment yield has a great decrease from the maximum yield, no great difference between NI and maximum earnings is observed. And with maximum of NUE, the embarrassing situation -local farmers do not see actual income increase except for the great increase of crops production - can be avoided. The nitrogen input also has a significant decrease comparing with local frequently-used nitrogen input. Since W\&N using efficiency is relatively high, it is believed that with $50 \%-75 \% \theta$ soil moisture content and $0.25 \mathrm{~kg} /$ plant nitrogen input, it is reasonable for the comprehensive benefits of jujube yield, NI and $\mathrm{W} \& \mathrm{~N}$ using efficiency to reach maximum.

\section{Conclusions}

The effects of different W\&N inputs on jujube yield, NI, WUE and NUE all reached the significant level. Various factors including the synergistic effects of $\mathrm{W} \& \mathrm{~N}$, water saving and nitrogen reduction, yield and income increase should all be considered comprehensively. Under the conditions of SRI fertilization, jujube yield had positive relationship of correlation with $\mathrm{W} \& \mathrm{~N}$ input. When $\mathrm{W} \& \mathrm{~N}$ input exceeded a certain range, NI started to decrease while the continuous increase of yield. Decrease of WUE and increase of NUE can be achieved by increasing the soil moisture content and lowering nitrogen input. The treatments corresponding to the maximum value of jujube yield, NI and W\&N using efficiency were different. The result based on weighted grey correlation evaluation showed that in two years, with $50 \%-75 \% \theta$ soil moisture content and $0.25 \mathrm{~kg} / \mathrm{plant}$ nitrogen input, the comprehensive benefits of jujube yield, NI, WUE and NUE could be maximized.

\section{Acknowledgements}

This study was financially supported by the National Key R \& D Program (No. 2016YFC0400204) and by the National Natural Science Foundation of China (No. 51279157).

\section{[References]}

[1] He Z J, Dong Q G, Yang K, Fu Y L, Fei L J. Water demand law and irrigation requirement of Jujube in Loess Plateau region. Water Saving Irrigation, 2017; 12: 33-38. (in Chinese)

[2] Han J Q, Gao J N, Luo H. Changes and implications of the relationship between rainfall, runoff and sediment load in the Wuding River basin on the Chinese Loess Plateau. Catena, 2019; 175: 228-235.

[3] Zhang J Q, Yang M Y, Deng X X, Liu Z, Zhang F B. The effects of tillage on sheet erosion on sloping fields in the wind-water erosion crisscross region of the Chinese Loess Plateau. Soil \& Tillage Research, 2019; 187: 235-245.

[4] He Z J, Wu M. Crop coefficient and water consumption rule of jujube trees in surge root irrigation of Loess Plateau region. Journal of Irrigation and Drainage, 2018; 37(2): 5-9. (in Chinese)

[5] Zeng J. Study on water consumption characteristics and irrigation system of apple trees in surge root irrigation in Loess hilly and gully region of Northern Shaanxi Province. Xi'an: Xi'an University of Technology, 2018. (in Chinese)

[6] Che Y W, Yang Q, Dai S D, Hu T T, Zhu D L. Effects of surge root irrigation on yield and quality of jujube in hills. Acta Agriculturae Boreali-occidentalis Sinica, 2013; 22(11): 108-113. (in Chinese)

[7] Liu H G, He X L, Li J, Li F D, Gong P, Zhang J, Yang G. Effects of water-fertilizer coupling on root distribution and yield of Chinese Jujube trees in Xinjiang. International Journal of Agricultural and Biological Engineering, 2017, 10(6): 103-114.

[8] Wang Z H, Bian Q Y, Zhang J Z, Zhou B. Optimized water and fertilizer management of mature jujube in Xinjiang arid area using drip irrigation. Water, 2018; 10(10): 1-13.

[9] Wang H D, Wu L F, Cheng M H, Fan J L, Zhang F C, Zou H Y, Chau H, Gao Z J, Wang X K. Coupling effects of water and fertilizer on yield, water and fertilizer use efficiency of drip-fertigated cotton in northern Xinjiang, China. Field Crops Research, 2018; 219: 169-179.

[10] Guan H, Li J, Li Y. Effects of drip system uniformity and irrigation amount on cotton yield and quality under arid conditions. Agricultural Water Management, 2013; 124: 37-51.

[11] Wu L F. Study on Coupling Effect and growth simulation of water and fertilizer in cotton fertigation in Xinjiang. Xi'an: Northwest A\&F University, 2015. (in Chinese)

[12] Pan N, Shen H, Wu D M, Deng L S, Tu P F, Gan H H, et al. Mechanism of improved phosphate uptake efficiency in banana seedlings on acidic soils using fertigation. Agricultural Water Management, 2011; 98(4): 632-638.

[13] Pan J F, Liu Y, Zhong X H, Lampayan R M, Singleton G R, Huang N R, Liang $\mathrm{K} \mathrm{M}$, et al. Grain yield, water productivity and nitrogen use efficiency of rice under different water management and fertilizer- $\mathrm{N}$ inputs in South China. Agricultural Water Management, 2017; 184: 191-200.

[14] Niang A, Becker M, Ewert F, Tanaka A, Dieng I, Saito K. Yield variation of rainfed rice as affected by field water availability and $\mathrm{N}$ fertilizer use in central Benin. Nutrient Cycling in Agroecosystems, 2017; 110(2): 
293-305

[15] Mamun Hossain S A, Wang L X, Liu H S. Improved greenhouse cucumber production under deficit water and fertilization in Northern China. Int $\mathrm{J}$ Agric \& Biol Eng, 2018; 11(4): 58-64.

[16] Rathore V S, Nathawat N S, Bhardwaj S, Sasidharan R P, Yadav B M, Kumar M, et al. Yield, water and nitrogen use efficiencies of sprinkler irrigated wheat grown under different irrigation and nitrogen levels in an arid region. Agricultural Water Management, 2017; 187: 232-245.

[17] Yang Z D, Li Z J, Liang H P, Zhang R. Preferred seepage channel identification based on multifactorial gray correlation analysis. Chemistry and Technology of Fuels and Oils, 2018; 54(5): 232-245.

[18] Roy M, Vachon-Presseau É. Grey correlations: a commentary on Chehadi et al. European Journal of Pain, 2018; 22(6): 1029-1031.

[19] Li Z M, Liang X D, Yin H D. A multi-criteria group decision making method for elevator safety evaluation with hesitant fuzzy judgments. Applied and Computational Mathematics, 2017; 16(3): 296-312.

[20] Koundinya AVV, Pandit M K, Ramesh D, Mishra, P. Phenotypic stability of eggplant for yield and quality through AMMI, GGE and cluster analyses. Scientia Horticulturea, 2019; 247: 216-223.

[21] Deng J L. Foundation of grey theory. Wuhan: Huazhong University of Science and Technology Press, 2002. (in Chinese)

[22] Yang Z L, Chu T S, Han L J, Liu X, Xiao W H, Huang G Q. Application of GC-TOPSIS on optimizing choice of utilization programs of crop straw. Transactions of the CSAE, 2013; 29(20): 179-191. (in Chinese)

[23] Wang S S, Wang K S, Liu D X, Li H H. Optimization of furrow irrigation mode for summer maize based on weighted grey correlation model. Transactions of the CSAE, 2016; 32(18): 133-139. (in Chinese)

[24] Zhao L Q, Guo Y M, Zhang P Z, Han Z S. Correlation degree analysis and gray clustering evaluation on performance indices of wheat no-tillage planter. Transactions of the CSAE, 2011; 27(9): 54-57. (in Chinese)

[25] Yagmur L, Aydemir B. A comparative study for material selection of sensor element using analytic hierarchy process. Mapan - Journal of Metrology Society of India: Preface, 2018; 33(4): 459-468.

[26] Ahmad L, Verma M K. Application of analytic hierarchy process in water resources planning: a GIS based approach in the identification of suitable site for water storage. Water Resources management, 2018; 32(15): 5093-5114.

[27] Irmak S, Djaman K, Rudnick D R. Effect of full and limited irrigation amount and frequency on subsurface drip-irrigated maize evapotranspiration, yield, water use efficiency and yield response factors. Irrigation Science, 2016; 34(4): 271-286.

[28] Wei Q, Assinck F B T, Heinen M, Oenema O. Water and nitrogen use efficiencies in citrus production: A meta-analysis. Agriculture, Ecosystems and Environment, 2016; 222: 103-111.

[29] KuraiT, Morey S R, Wani S P, Watanabe T. Efficient rates of nitrogenous fertiliser for irrigated sweet sorghum cultivation during the post-rainy season in the semi-arid tropics. European Journal of Agronomy, 2015; 71: 63-72.

[30] Wang D B, Li F S, Nong M L. Response of yield and water use efficiency to different irrigation levels at different growth stages of Kenaf and crop water production function. Agricultural Water Management, 2017; 179: 177-183.

[31] Liu G H, Ma Y J, Wang Z Y, Xie X W. Research on the Effect of different fertilization levels on jujube growth and yield constituting factors under drip irrigation. Xinjiang Agricultural Sciences, 2016; 53(3): 481-487. (in Chinese)

[32] Santeramo F G, Goodwin B K, Adinolfi F, Capitanio F. Farmer participation, entry and exit decisions in the Italian crop insurance programme. Journal of Agricultural Economics, 2016; 67(3): 639-657.

[33] Seassau C, Dechamp-Guillaume G, Mestries E, Debaeka P. Nitrogen and water management can limit premature ripening of sunflower induced by Phomamacdonaldii. Field Crops Research, 2010; 115: 99-106.

[34] Todorovic M, Mehmeti A, Cantore V. Impact of different water and nitrogen inputs on the eco-efficiency of durum wheat cultivation in mediterranean environments. Journal of Cleaner Production, 2018; 183: 1276-1288.

[35] Xing Y Y, Zhang F C, Zhang Y, Li J, Qiang S C, Wu L F. Effect of irrigation and fertilizer coupling on greenhouse tomato yield, quality, water and nitrogen utilization under fertigation. Scientia Agricultura Sinica, 2015; 48(4): 713-726. (in Chinese)

[36] Doring T F, Reckling M. Detecting global trends of cereal yield stability by adjusting the coefficient of variation. European Journal of Agronomy, 2018; 99: 30-36.

[37] Suo Y, Wang Z J. Systematically evaluating the performance of typical water-saving irrigation techniques. Journal of Irrigation and Drainage, 2018; 37(11): 113-120. 